\title{
STUDIES ON CHILD GRAMMAR
}

\author{
Jeanette Bloom, B.A. Log. (Rand)
}

The general hypothesis on which work in the field is based, is that child speech is a systematic reduction of adult speech, largely accomplished by omitting 'function' words that carry little information. From this corpus of reduced sentences, the child induces general rules which govern the construction of new utterances. As a child becomes capable, through maturation and the consolidation of frequently occurring sequences, of registering more of the detail of adult speech, his original rules will be revised and supplemented. As the generative grammar grows more complicated and more like adult grammar, the child's speech will become capable of expressing a greater variety of meanings.

Brown and Bellugi ${ }^{2}$ suggested that the model sentence is processed by the child as a total construction rather than as a list of words. In their study, the child's imitations preserved the word order of the model sentences. There is a constraint, a limitation on the length of utterance the child is able to program or plan. Constraint on length compels the imitating child to omit some words or morphemes from the model sentences. Differential stress was felt to be a possible cause of the child's differential retention. Brown and Fraser ${ }^{4}$ list the morphemes likely to be retained in the child's speech. Ervin ${ }^{9}$ having studied children's imitations systematically to see if they are grammatically different from free utterances, concluded that, we cannot look to overt imitation as a source for the rapid progress children make in grammatical skill in these early years.

Certain utterances in a child's language are bound to be imitations of adult sentences. However all children are able to understand and construct sentences they have never heard. These sentences are well-formed in terms of general rules implicit in the sentences the child has heard. The child processes the speech to which he is exposed. He induces the latent structure.

Braine, ${ }^{1}$ Brown and Bellugi,"- Brown and Fraser ${ }^{4}$ and Miller and Ervin ${ }^{14}$ have been concerned with devising a set of rules which would account for the material presented in their studies, as well as to predict new sentences -a generative grammar.

Braine's study will be mentioned here, since on his findings is based the model of analysis used in the present study. By examining the word combinations and privileges of occurrence in his samples, he derives two main word classes. These he labels 'pivots' and ' $\mathrm{x}$-words'. Pivots are few in number, occur in several word combinations and each is associated with a particular position, either initial or final. X-words form a large, open class, containing all the rest of the child's vocabulary. The child's single- 
word utterances are drawn from the x-class. The class of pivot words $P_{I}$ is broken down into $P_{1}$ (initial position) and $P_{2}$ (those which occur in final position). Thus on the basis of privileges of occurrence, it is possible to construct a set of parts of speech and also a syntax which governs the ordering of these parts of speech.

Syntactic rules which summarize most of the speech here are: utterance $=\mathrm{P}_{1}+\mathrm{X}$ or $\mathrm{X}+\mathrm{P}_{2}$. Class $\mathrm{PI}_{\mathrm{I}}$ and class $\mathrm{x}$ can occur together, and class $\mathrm{PI}$ always precedes class $\mathrm{x}$. Class $\mathrm{P}_{2}$ and $\mathrm{x}$ can occur together, and $\mathrm{P}_{2}$ always follows $x$. This is a simple generative grammar.

Brown and Fraser ${ }^{*}$ used this approach to develop a developmental syntax. Laura Lee, ${ }^{10}$ also used this as a basis for her model of analysis (Table I), while Paula Menyuk ${ }^{11-13}$ studied children's use of transformations.

In the present study, the development of syntax from the 'Pivot-open class' construction to the formation of kernel sentences at the phrase structure level of grammar, is considered.

\section{A Comparison of the Syntactic Structures of a Normal and an Articulation-Defective Three-Year-Old}

This'study is concerned with the child's acquisition of syntax. It is not concerned with the cognitive aspects of language, with conceptualization, or with receptive-expressive phenomena. It deals entirely with the speech output of the child; and with its systematization of that output into hypothetical stages, from the appearance of single-word utterances, to the formation of adult, grammatically acceptable sentences.

Before describing the development of a child's grammar, it is necessary to specify the properties of natural languages as used by adults, since this is the model presented to the child and the eventual outcome of his development.

From a structural point of view, every natural language is constructed from a small number of distinctive elements, namely vowels and consonants, levels of pitch, pauses and stresses. These make up the phonemes of a language. ${ }^{3}$ All natural languages have a finite number of phonemes and each sentence can be represented as a finite sequence of these phonemes, though there are infinite sentences. ${ }^{7}$ Every natural language is a system. From knowledge of one part of the language, it is possible to anticipate correctly many other parts. The system of language may be divided into sub-systems. Descriptions of language are achieved by dealing with each sub-system as a separate level of representation.

I. Phonological Level. On this level, the phonemes of a language and the permitted patterns of the combinations of phonemes are enumerated. One language never includes all the conceivable patterns of combinations. In English, for example, one may not combine phonemes / $\mathrm{y} / \mathrm{and} / \mathrm{k} /$ to produce / $\mathrm{nk} /$ at the beginning of a syllable, while at the end of a syllable this is permitted. The phonological system may be described in 


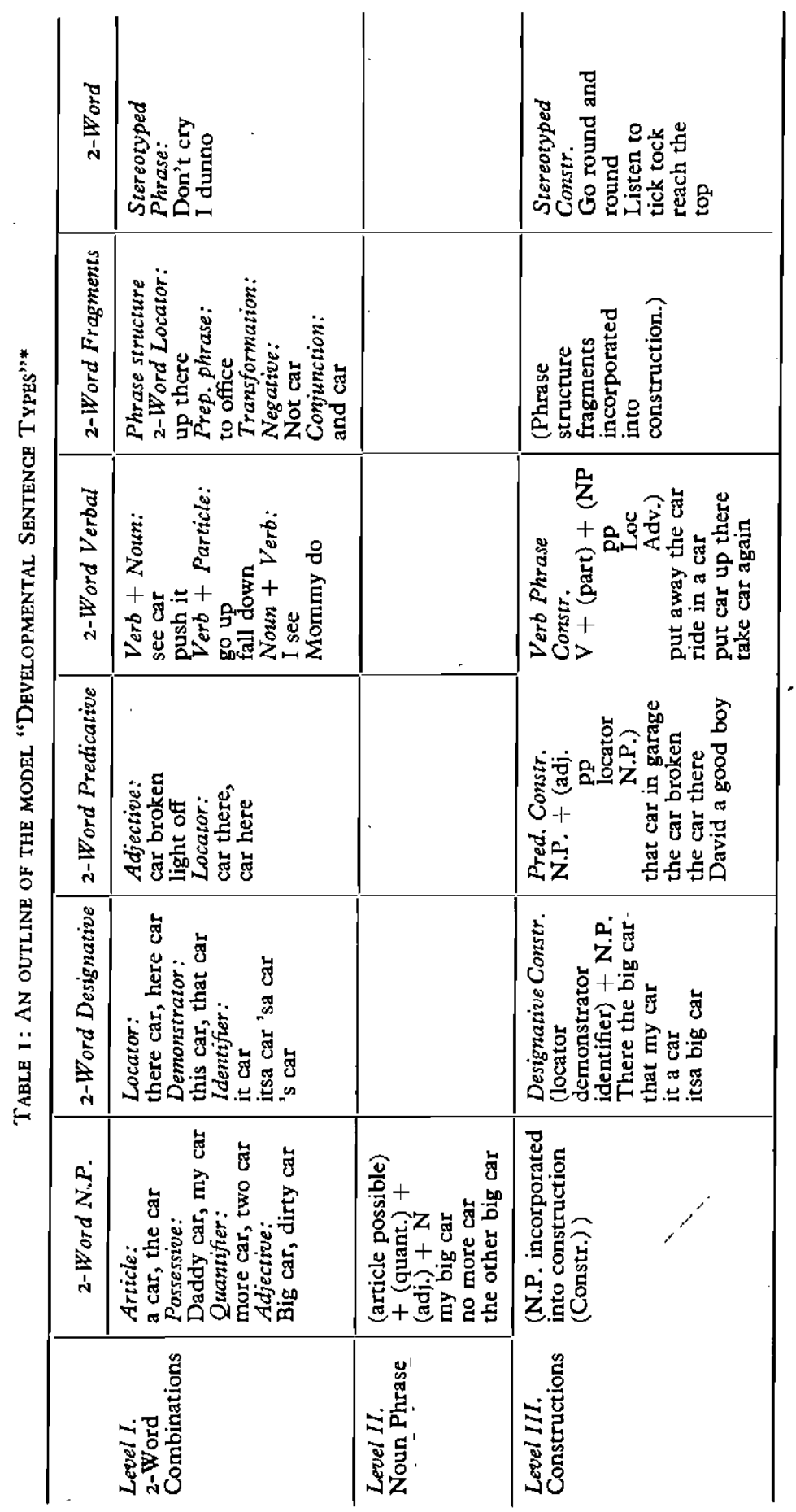

Fournal of the South African Logopedic Society, Vol. I5, No. I: December 196 


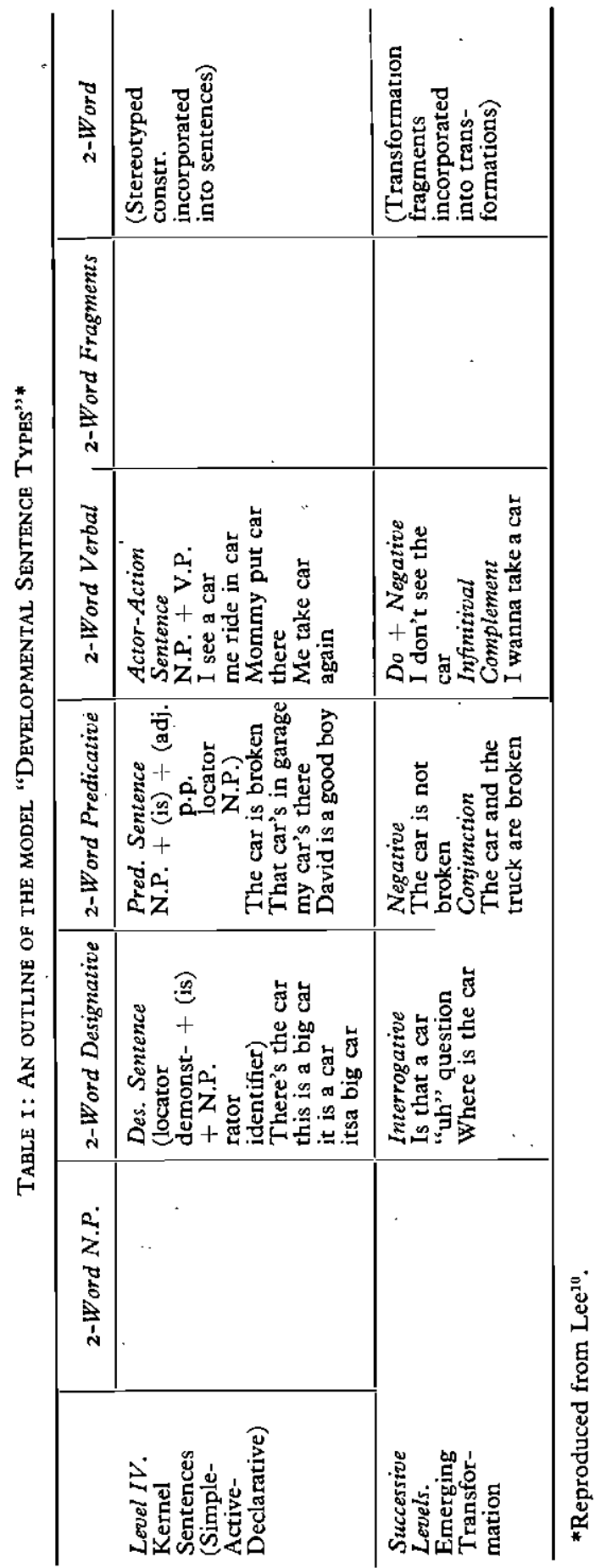

Tydskrif van die Suid-Afrikaanse Logopediese Vereniging, Vol. 15, Nr. I: Des. 1968 
terms of the different privileges of occurrences of features or sets of features called phonemes. ${ }^{14}$

2. Morphological Level. On this level, the morphemes of a language and their rules for combination are enumerated. Morphemes are the smallest individually meaningful elements in the utterances of a language.

Allomorphs, the sound representations of morphemes, obey certain rules of distribution, i.e. they are phonologically conditioned. One allomorph occurs in a particular phonetic environment in which the others do not.

3. Syntactic Level. On this level, the construction of sentences by the combination of words into various permitted patterns is described.

On all three levels, the patterning of elements into certain permitted combinations, i.e. the patterned structure of language, is evident. The present study is concerned with how a child acquires the patterns of English.

How does the child's grammar converge on the norm of the community in which he lives? Operant conditioning and reinforcement by the responses of others, together with adult correction of errors, is one source of change. However this does not take account of the fact that a child may say things no-one has taught him. ${ }^{9}$ Similarly, it is unlikely that a child masters a language on the basis of imitation alone. The presence of grammatical errors yields evidence that the child makes sentences he is not likely to have heard. An understanding of how the child acquires language brings us into the field of generative grammar.

Generative Grammar. The generative grammar model, as described by Chomsky" considers grammar as having a tripartite structure:

(a) a phrase-structure level.

(b) a transformation level.

(c) a morphological level.

Each of these three levels has a sequence of rules which generate the form of sentences within the level. At the phrase-structure level, the parts of speech combine to form simple-active-declarative sentences of the type, 'I play'. These are called terminal strings or kernel sentences and form the basis for all other sentences.

At the transformation level, rules will change the order of the symbols in the kernel sentence, or will allow symbols to be deleted or added. Thus, from the kernel sentences of English, one could generate the sentence, 'I play.' Transformational rules would then operate to turn, this into the negative 'I do not play' or interrogative 'why do I play?'?

At the morphological level of grammar, there is a sequence of inflectional rules which formulate, for example, the third person, present tense, singular of the verb.

The present study is concerned with the development of sentences from the level of single-word utterances to the formation of kernel sentences at the phrase-structure level of grammar. The speech output of both a normal and an articulation-defective child are analyzed in this way.

fournal of the South African Logopedic Society, Vol. 15, No. 1: December 1968 


\section{Methodology of the Present Study}

r. Rationale. From a structural point of view, language is described by linguists in terms of three inter-related systems: phonological, morphological and syntactic. Inadequate learning of the phonological system, resulting in the disorder to which speech pathologists refer as 'general, dyslalia' would suggest a corresponding inadequacy of either or both of the two remaining systems.

Considering it from a generative grammar point of view, language is regarded by Noam Chomsky ${ }^{6}$ as a set of sentences constructed out of a finite set of elements or phonemes. From this statement, arises the suggestion that a defect involving the elements or phonemes of a language, would affect sentence construction.

Clinical observation of children who appear to have delayed speech, frequently reveals the presence of numerous articulation errors in conjunction with immature sentence construction, implying a possible relationship between articulation and syntactic abilities.

These suggestions invite exploration of such a relationship in an experimental fashion, the information so derived being of value to a speech pathologist concerned with the improvement of a child's linguistic skills. The writer has therefore attempted an investigation of the syntactic structures of a previously diagnosed 'general-dyslalic' child, in relation to that of a child whose speech is characterized by absence of articulation errors. The study is carried out with the hypothesis that the general-dyslalic child will have syntactic structures which deviate from those of the normal child, as revealed by the model of analysis used. The writer has adopted a generative grammar model of analysis, viz: developmental sentence types as devised by Laura Lee. ${ }^{10}$ This type of analysis was chosen in preference to those of traditional grammar and the McCarthy-Templin-Davis approach, because the former approach was considered to be based on an unscientific systematization of language; the latter to be more useful when dealing with normative data or quantitative results, rather than qualitative information required for therapy. The chosen approach was expected to give valuable quantitative information regarding phase and type of syntactic deviation; and served to utilize the field of psycholinguistics in the investigation of a problem pertaining to speech therapy.

Hypothesis. The general-dyslalic child under investigation will have syntactic structures which differ from those of a normal child of the same age, sex, socio-economic status and intelligence.

\section{PROCEDURE}

Subjects. Two female subjects each aged three years were used. Gillian, the general-dyslalic child, was three years five months at the time of investigation. Debbie, the normal child, was three years three months.

Gillian was selected because her speech included numerous articulation errors which could not be attributed to any organic cause. She showed no 
evidence of brain injury, mental retardation, hearing defect or emotional disturbance. Her articulation errors included:

Substitutions: $\begin{array}{rlrr}\mathrm{t} \int / \mathrm{g} & \mathrm{d} 3 / \mathrm{d} & \int / \mathrm{s} & \mathrm{g} / \mathrm{z} \\ \mathrm{t} \int / \mathrm{d} & \mathrm{g} / \mathrm{d} & \int / \mathrm{sw} & \mathrm{t} / \mathrm{s} \\ \mathrm{t} \int / \mathrm{t} & \mathrm{d} / \mathrm{z} & \int / \mathrm{sm} & \mathrm{k} / \mathrm{p} \\ \mathrm{t} / \theta & \mathrm{d} / \mathrm{g} & \int / \theta & \mathrm{t} / \mathrm{k}\end{array}$

Omissions: /1/ initially and medially,

/h/ initially and medially,

/n/ initially,

$/ \mathrm{m} /$ initially,

/s/ initially and finally,

$/ \mathrm{r} /$ initially, medially and finally,

/s / initially,

/g/ initially,

/d/ medially and finally.

Distortions: Vowels were distorted so that

/a/ approximated $|\Lambda|$

$|\partial|$ approximated $|x|$

General trends appear to be a substitution of $\left[\mathrm{t} \int\right]$ and $\left[\int\right]$ for stops and fricatives, omission of initial consonants and distortion of vowels. Errors were very inconsistent however, and a sound which frequently substituted for another, might be omitted on some occasions. Words were telescoped e.g. 'cigarette' was pronounced 'iaette' in the sample. Furthermore, the child was receiving therapy at the time the sample was taken, and had recently started to show ability to make sounds correctly, upon stimulation.

The child had only recently begun to talk, but was using sentences at the time of investigation. She attended the University of the Witwatersrand Speech, Voice and Hearing Clinic. Her case history revealed that her parents came from an upper middle-class income group, as indicated by residential address and paternal occupation. She was judged by her therapist to be of normal intelligence, although this was not formally tested. She was the youngest child and was exposed to English only, at home.

Debbie was selected from the nursery school attached to the Nursery School Teachers' Training College, in Johannesburg. She was a member of the junior class, the three to five year age group. She was chosen among all others in the group because her background most closely resembled that of Gillian. She was the eldest child of a monolingual family. She was exposed to English only at home. She came from a neighbourhood very near to that of Gillian, being of the upper middleclass income group. She had been attending nursery school for three months and was judged by her teacher to be of normal intelligence although this was not formally tested.

Fournal of the South African Logopedic Society, Vol. 15, No. I: December 1968 
Debbie appeared to have no history of delayed speech, as indicated by the nursery school records, and her speech was characterized by absence of all articulation errors at the time the sample was taken.

2. Materials. Stimulus material consisted of a set of pictures obtained from a child's story book: Gagg, M. E. 'The Party' A Ladybird Learning To Read Book Series 563, Wills and Hepworth Ltd., Loughborough, England, I960.

A set of ten brightly coloured, realistic pictures, each $4^{\prime \prime} \times 7^{\prime \prime}$ was removed from the book and pasted on to a large cardboard, in sequence, so that the subject could follow the story told by the investigator.

3. Method. Subjects were tested individually, in familiar surroundings. Gillian was tested during her therapy session, in the presence of her therapist. Both therapist and investigator participated in eliciting the responses. The testing situation was not unlike the child's usual therapy sessions. Debbie was tested at nursery school with a few friends present. She was tested in a familiar room during the play hour when it is quite usual for a group of children to gather round one of the student teachers, to look at pictures and talk.

The investigator spent ten minutes playing with the children before the sample of utterances was tape-recorded. This gave the subject the opportunity of overcoming shyness, which would have influenced the sample. The investigator then offered to tell a story about the pictures to each child. The story was told to each in exactly the same way using the same wording. The sentences of the story were constructed so as to represent all types of constructions used in the model of analysis. Sentences were above the level of the simple, declarative type the level IV kernel sentences represented in the model. Many transformations were introduced to make the stimulus more like that of adult speech to which the child is normally exposed. Language was kept simple, and the vocabulary limited to the type most children have experienced by three years of age. The story pertained to a birthday party, selected because this subject-matter is within the range of most children's experience.

The investigator told the story in an interesting voice, tracing the development of the story with her finger, on the pictures, pointing out each item with her finger in order to maintain interest and make sure the child understood her. The child was then asked to tell the investigator the story. This required a little prompting and encouragement, in the case of both children.

The picture-story was introduced as a control in the experiment, so that the stimulus conditions would be the same for each child and responses would differ only in the syntactic structures used, vocabulary and language content remaining constant. The presence of the pictures was designed to eliminate the variable of memory.

The samples of utterances (corpora) so obtained, were tape-recorded, then written out in traditional orthography and analyzed.

A corpus of fifty utterances was derived for each child, because the 
literature ${ }^{\delta}$ suggests that this number of utterances is satisfactory for obtaining a reliable measure of language structural complexity. This was discovered however to be a grave methodological flaw regarding the nature of analysis used in this study. The number of sentences is insufficient to reflect a child's linguistic competence. Chomsky ${ }^{5}$ points out the inadequacy of attempting to derive a child's grammar on the basis of a corpus of utterances however large. One cannot say that the child lacks a particular construction, because he has not used it in the corpus especially when the corpus consists of only fifty utterances. A comparison therefore, was made between the syntactic structures used by the two children in this particular situation and no inferences regarding linguistic competence were made.

4. Analysis. The model of analysis used was that developed by Laura Lee $^{10}$ termed Developmental Sentence Types. A reproduction of the table of this model appears in Table I. An explanation of the table is included here, since this is the analysis used by the writer, in an unmodified version.

The child has been speaking up to this stage, in single word utterances. At level I he now combines two words into a pivot-open class construction, as discussed above. The two-word combinations are classified according to the type of pivot used. Where the pivot is an article, possessive pronoun, quantifier or adjective, it combines with a noun to form a twoword noun phrase. Where the pivot is a locator 'here', 'there', demonstrator 'this', 'that' or identifier 'it', 'it's a' its combination with a noun is termed a 2-word designative construction. Designators are words which accompany or replace a gesture. Where the pivot describes the item of attention, therefore predicating information about it, its combination with a noun becomes a two-word predicative construction. Where a two-word combination consists of a noun and a verb, a verb and a noun or a verb and a particle, the construction so formed is termed a two-word verbal. The child may say two-word utterances which are more imitative of adult grammar, some of which are the forerunners of transformations and some of which will be incorporated at the phrase-structure level. These are 'fragments', they do not themselves expand into sentences, but must be incorporated into other constructions, e.g.: 'up there', 'to office'. There are two-word 'combinations which are mere imitations of adult stereotyped phrases, e.g.: 'be careful'. This varies from one child to another depending on the adult speech to which he is exposed. They are termed stereotyped phrases.

Level I: Here we observe the emergence of miniature adult syntactic forms. Subsequent levels of developmental sentence types démonstrate the expansions and rearrangements of these basic two-word combinations.

Level II-The Noun Phrase: Here, certain pivot words become differentiated by privilege of occurrence into articles, possessive nouns and pronouns, numbers or adjectives. Two or more former pivots may be used, each with its special location in the string. Conventional sequences and combinations are learned very gradually. Once developed, the entire noun phrase may be moved from one position to another in a longer string, or may be lifted out entirely and replaced by a pronoun. 
Level III-Constructions: Designative Constructions. A locator, identifier or demonstrator is added to a noun phrase. Thus at Level I, the twoword designative construction 'there car', becomes expanded at Level III to 'there the big car'.

Addition of an adjective, prepositional phrase, locator after the noun phrase or second noun phrase, to a noun phrase, makes a predicative construction. A predicative construction names the item of attention and then 'predicates' something further about it. This additional information may take many forms: adjective, locator etc. This must not be confused with the designative construction where the noun phrase comes last in the string. Addition of a noun phrase, prepositional phrase, locator and adverb, together with an optional particle, to a verb, forms a verb phrase construction. The verb phrase may be further extended by combining more of these components, e.g.: 'Put on the hat again' (verb + particle + noun phrase + adverb). Stereotyped constructions are included to account for a few often-repeated phrases which children pick up without understanding the component words as individual semantic units.

Level IV-Sentences: Designative Sentences are formed by the addition of 'is' between the designative word (locator, demonstrator, identifier) and the noun phrase. Similarly a predicative sentence is formed by adding 'is' between a noun phrase and an adjective, prepositional phrase, locator or second noun phrase. Actor-Action Sentences are formed by adding a verb phrase to a noun phrase. This is the development of two-word combinations into kernel sentences of the simple, active, declarative type-sentences at the phrase-structure level.

This model was chosen because it was expected to yield differences in terms of level of development between the syntactic structures used by the two children. It was expected that a knowledge of the type of construction as well as of the level of development of that construction, on which the child 'fell down' would be of value in constructing a therapy program.

\section{RESULTS AND DISCUSSIONS}

The analyses of the two corpora will not be presented in this article, but rather a brief comparison of the two corpora will be given. For a more detailed account the reader is referred to the original thesis $A$ Comparison of the Syntactic Structures of a Normal and an Articulation Defective three year old. J. Bloom (r967).

Single Word Utterances. Although the bulk of these were not included in the sample, because of their mode of elicitation and because they would weigh the sample heavily, they were listed and considered for comparison purposes. Gillian answered many questions with single-word replies, where more complete responses were possible. Debbie used far less one-word sentences. Of the single-word utterances included in the samples, both children used the same number and kind.

Level I: Two-Word Combinations. Both children used the same number of two-word noun-phrases. Gillian used no articles in her corpus 
while Debbie used both 'the' and 'a' correctly. Gillian used many twoword verbals. This construction was quite evident in her corpus, but often atypical e.g. 'is walking' meaning 'Susan is walking'. According to Brown and Bellugi ${ }^{2}$ it is the stressed morphemes which should be reproduced rather than the unstressed ones.

Both children showed lack of designative constructions, and both showed emerging transformations at this level. Lee ${ }^{10}$ feels that these constructions are too inconsistent and immature to be called transformations at this stage.

Level II: Noun Phrases. Debbie used no noun phrases. She appeared to have passed beyond this level, for she incorporated noun phrases into her sentences. Gillian used noun phrases, and showed another type of atypical construction, i.e. reversed word order, e.g. 'cake happy birthday' in imitation of 'happy birthday cake'.

Level III: Constructions. Gillian, who did not have the designative construction at Level I, still showed no examples of this construction at Level III. For Gillian, designators had not yet appeared in her vocabulary, therefore could not be incorporated into constructions; Debbie used no designative constructions either, but might be said to have passed beyond this level, since designators appear in sentences at Level IV.

Verb phrase constructions appeared to be the most popular for both children. This would follow from the fact that two-word verbals were the most evident at Level I. This is in keeping with a developmental theory.

Level IV: Sentences. Debbie used a large number of sentences in her speech. The bulk of her corpus was at this level. She also used a variety of transformations and many items appeared to be beyond the phrase-structure level, as compared with the transformational sentences listed by Menyuk.

Gillian used a number of Level IV sentences, though not as many as Debbie, and these were not syntactically correct. 'Is to party' is an unusual construction in that the verb 'to be' and the preposition is included, while the usually stressed forms, 'John (Susan)' and 'going' are omitted; the model sentence being Fohn and Susan are going to a party.' Similarly 'has a work it' which appears to have meant, 'he's working'.

From the two corpora examined, limited as they are, certain trends are apparent.

(a) The technique was expected to show up developmental trends. Where two-word verbals were used at Level I, actor-action sentences were predominant at Level IV. Where designators were few or nonexistent at an earlier stage, they did not appear at successive stages. Other structures appear to have developed ahead of designative and predicative constructions.

(b) Though the children used roughly the same proportion of various constructions to the whole corpus, they differed in the kind of structures used. This was fairly marked and may not have been revealed using the McCarthy approach. 
(c) While a morphological analysis of the corpora was not done. Gillian showed the same irregularity in her morphemic constructions, e.g. attaching the verbal suffix to the noun rather than the verb: 'Mommys feed him'.

(d) One cannot say, on the basis of the sample obtained, that Debbie, for instance, has no predicative constructions in her grammar. To arrive at such a conclusion, one would have to ask her to repeat certain sentences involving predicative constructions, or answer questions in such a way that predicators must emerge in the responses. One can say, however, that she has not used any in the corpus, and that she does not appear to have developed this type of construction. Only by testing for the presence or absence of constructions by using nonsense syllables for instance, can a statement regarding the linguistic competence of the subject be made. The writer has not arrived at a grammar for Gillian or Debbie, but has demonstrated that on comparison of their syntactic structures, the generaldyslalic child differed qualitatively from the normal three-year-old.

\section{Conclusion}

Every therapist is familiar with the disorder known as General Dyslalia. She is familiar with techniques for analysis of articulation errors, and has at her disposal literature on therapeutic techniques for the teaching of phonemic contrasts the child has failed to make. But what of sentence construction? Is she familiar with techniques for analysis of sentences? Is there literature available on the methodic, systematic building-up of sentences in children who have failed to do so spontaneously? Would she recognize that the child has syntactic deviations in the first place? How would she know that they were deviant? With what would she compare them? In fact, has she knowledge of the normal development of syntax?

Such a knowledge becomes necessary when dealing with languagedefective cases. If we are to be experts on communication and its disorders, we must know exactly how we come to use the sentences we do; for this, after all, is the way in which we communicate.

We give 'general language stimulation' at the one-word level, to our speech-delayed children. We build up a basic vocabulary of nouns and verbs. We may take them through to the two-word stage, by using twoword sentences ourselves, probably unwittingly exploiting the principles of generative grammar. But what of the child who is beyond the two word-level, whose language may be by no means adequate? What of the dysaudic and aphasic? If, in the latter case, we are to build up those constructions which have broken down because of a disturbance of the linguistic processes owing to brain injury, we must have knowledge of the type of syntactic deviations revealed and how these can be systematically and methodically built up. In the case of the dysaudic, it is essential to be systematic in the type of syntax one presents to the patient, since he must imitate and induce a latent structure from sentences presented to him 
under reduced auditory cues. He must be taken systematically through the stages of the normal development of syntax.

For these reasons, the therapist must have knowledge of the normal development of syntax. Models such as the one described above, are of great value, but these have not yet been validated. She looks to the field of psycholinguistics, to provide her with the information she needs, for the future.

\section{Summary}

A corpus of utterances was derived from a normal and an articulationdefective three-year-old female child, and was analyzed syntactically using a model of analysis based on a generative grammar approach. The speech output of the articulation-defective child was found to be qualitatively different from that of the normal child. While the small number of subjects, and the size of samples used irivalidate the study, the approach was found to yield valuable information regarding the diagnosis and treatment of language-defective cases.

\section{Opsomming}

Spraakvoorbeelde is verkry van twee drie-jarige dogters; een normaalsprekend en die ander met artikulasieafwykings. Die voorbeelde is sintakties geanaliseer deur gebruik te maak van 'n analise-skaal gebasseer op 'n generatief-grammatiese benadering. Daar is gevind dat die spraakproduksie van die kind met artikulasieafwykings kwalitatief verskil van dié van die normaalsprekende kind.

As gevolg van die feit dat net twee proef-persone gebruik is en die grootte van die spraakmonsters nie verteenwoordigend was nie, is die ondersoek nie geldig nie. Nogtans is waardevolle inligting aangaande die diagnose en behandeling van taalafwykende gevalle verkry.

\section{REFERENCES}

I. Braine, M. D. S. (1963): The Ontogeny of English Phrase Structure. Language, 39, I-I3.

2. Brown, R. and Bellugi, U. (1964): Three Processes in the Child's Acquisition of Syntax. Harvard Educational Review. 34, I33-I II.

3. Brown, R. and Berko, J.: Psycholinguistic Research Methods,' in Handbook of Research Methods in Child Development. Chapter 13 (éd.). Mussen; P.

4. Brown, R. and Fraser, C. (1964): The Acquisition of Syntax. Monagraphs of the Society for Research in Child Development, 29, I, 43-79.

5. Chomsky, N. (1964): Formal Discussion. Monographs of the Society for Research in Child Development, 29, I, 35-39.

6. Chomsky, N. (1957): Syntactic Structures. Mouton, The Hague.

7. Chomsky, N. The Independence of Grammar in Psycholinguistics: A Book of Readings. (ed.) Saporta.

8. Darley, F. L. and Moll, K. L. (I960): Reliability of Language Measures and Size of Language Sample. J. Speech' Hearing Research, 3, I66-173.

9. Ervin, S. M.: Imitation and Structural Change in Children's Language in New Directions in the Study of Language. (ed.). Lenneberg, F. H.

Fournal of the South African Logopedic Society, Vol. 15, No. I: December 1968 
ro. Lee, Laura (1966): Developmental Sentence Types: A Method for Comparing Normal and Deviant Syntactic Development. J. Speech Hearing Disorders, 31, 4, 3I I-33I.

II. Menyuk, P. (I963): Syntactic Structures in the Language of Children. Journal of Child Development, 34, 407-422.

2. Menyuk, P. (1964): Syntactic Rules Used By Children From Pre-School. Through First Grade. Child Development, 35, 533-546.

13. Menyuk, P. (1964): Comparison of Grammar of Children with Functionally Deviant and Normal Speech. J. Speech Hearing Research, 7, I09-I2I.

I4. Miller, W. and Ervin, S. (1964): The Development of Grammar in Child Language. Monographs for the Society for Research in Child Development, 29, I, 9-34.

Tydskrif van die Suid-Afrikaanse Logopediese Vereniging, Vol. I5, Nr. I: Des. 1968 